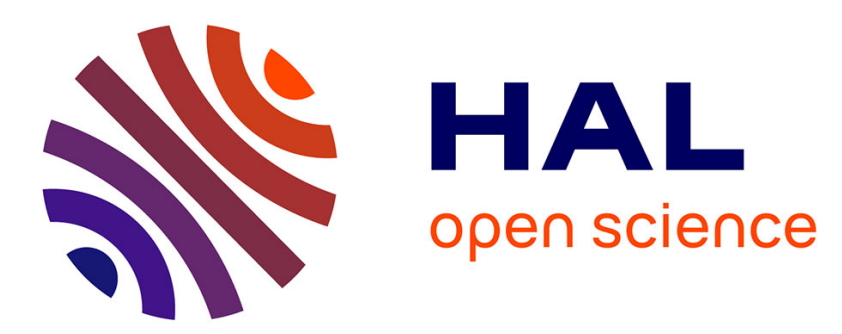

\title{
Force Measurement of Living Professional Phagocytes of the Immune System
}

Anna Mularski, Florence Niedergang

\section{To cite this version:}

Anna Mularski, Florence Niedergang. Force Measurement of Living Professional Phagocytes of the Immune System. Australian Journal of Chemistry, 2020, 73 (3), pp.104. 10.1071/CH19409 . hal03042133

\section{HAL Id: hal-03042133 \\ https://hal.science/hal-03042133}

Submitted on 7 Jan 2021

HAL is a multi-disciplinary open access archive for the deposit and dissemination of scientific research documents, whether they are published or not. The documents may come from teaching and research institutions in France or abroad, or from public or private research centers.
L'archive ouverte pluridisciplinaire HAL, est destinée au dépôt et à la diffusion de documents scientifiques de niveau recherche, publiés ou non, émanant des établissements d'enseignement et de recherche français ou étrangers, des laboratoires publics ou privés. 


\title{
Force measurement of living professional phagocytes of the immune system
}

Anna Mularski ${ }^{1,2,3}$ and Florence Niedergang ${ }^{1,2,3}$

1. Inserm, U1016, Institut Cochin, Paris, France.

2. CNRS, UMR 8104, Paris, France.

3. Université Paris Descartes, Sorbonne Paris Cité, Paris, France.

\begin{abstract}
In higher organisms, the professional phagocytes of the immune system (dendritic cells, monocytes/macrophages and neutrophils), are responsible for pathogen clearance, the development of immune responses via cytokine secretion and presentation of antigens derived from the internalized material and the normal turnover and remodelling of tissues and disposal of dead cells. These functions rely on the ability of phagocytes to migrate and adhere to sites of infection, dynamically probe their environments to make contact with phagocytic targets, and to perform phagocytosis, a mechanism of internalization of large particles, microorganisms and cellular debris for intracellular degradation. The cell generated forces that are necessary for the professional phagocytes to act in their roles as 'first responders' of the immune system have been the subject of mechanical studies in recent years. Methods of force measurement such as atomic force microscopy, traction force microscopy, micropipette aspiration, magnetic and optical tweezers, and exciting new variants of these, have accompanied classical biological methods to perform mechanical investigations of these highly dynamic immune cells.
\end{abstract}

\section{Introduction}

Phagocytosis is the cellular mechanism of the internalization of large particles, microorganisms and cellular debris that can be up to several microns in size (1). Single celled eukaryotes, such as amoebae and the slime mold, Dictyostelium discoideum, rely on phagocytosis for nutrition (2). In higher organisms, the professional phagocytes of the immune system (dendritic cells, monocytes/macrophages and neutrophils), are responsible for pathogen clearance, the development of immune responses via cytokine secretion and presentation of antigen derived from the internalized material and the normal turnover and remodelling of tissues and disposal of dead cells (3). These cells vary in size, morphology and the mode with which they carry out these vital immune functions, however all of these cells perform phagocytosis with great efficiency.

The ability of phagocytes to migrate to sites of infection is instrumental in their role as the 'first responders' of the immune system. Many immune cells migrate along chemical gradients to encounter and engulf phagocytic targets (4-6). The signaling mechanisms underlying migration have been determined in mesenchymal cells in particular $(7,8)$. According to a classification based on morphology and molecular players, cells with strong adhesion properties and protrusion activity at their leading edge are classified as 
belonging to the mesenchymal migration mode, while cells with a less adhered phenotype and a higher contractile activity have an amoeboid migration.

In mesenchymal cells, effective migration requires cells to attach to their surrounding environment and generate traction against the material of which the surrounding environment is composed. The cell then contracts, which exerts traction on the underlying substrate generating strong cellular forces at the cell's leading edge. The contraction is followed by the release of the cell's uropod and forward motion of the cell is achieved (9-11). This mode of cellular migration is referred to as 'the towing mechanism'. Mesenchymal cells form strong focal adhesions, integrin-based structures use adhere to the substrate and to serve as mechanosensors to sense local stiffness (12). These adhesions with the substrate contain stress fibers that enable the large cellular contractions required for their motility of mesenchymal cells (13). More recently though, studies have appeared that investigated the mechanical mechanism of migration and adhesion of the phagocytic cells of the immune system, which have long been known to migrate at greater speeds with different (and shorter-lived) adhesive architecture than the larger, highly contractile mesenchymal cells. These studies have revealed significant variation from earlier mechanistic studies of mesenchymal cells such as endothelial cells and fibroblasts. In addition, the physical properties of the cells' environment also play an important role in defining the migration type of immune cells. This is especially true for dendritic cells, as described in a recent review (14).

Not all phagocytes migrate to the sites of infection, some reside in niches such that phagocytic targets are encountered via the directed movement of lymph or blood flow, this can be a passive or stochastic event. (15-17). However, both migratory and nonmigratory phagocytes also actively survey their environment with continuous, dynamic probing to maximise encounters with phagocytic targets: phagocytic cells must be in physical contact with their target as phagocytosis is initiated by the triggering of surface receptors. Phagocytes probe their environments with actin driven protrusions, the result of the dynamic formation and disassembly of actin networks directly under the membrane surface. Flannagan et al. have demonstrated that these membrane protrusions greatly enhance the frequency of receptor engagement with stationary or randomly moving target particles (18). Cells that were unable to form these membrane protrusions failed to engage stationary particles $(18,19)$. Indeed, Nimmerjahn et al. (20) demonstrated that membrane protrusions allow phagocytes to increase their scanning radius by allowing access to spaces their cell bodies cannot access.

Once phagocyte and target are in physical contact, phagocytosis can be initiated by the triggering of surface receptors for opsonins like immunoglobulins (IgG), in the case of the $\mathrm{Fc}$ receptor $(\mathrm{FCR})$ mediated phagocytosis, or complement, in the case of integrin $(\alpha \mathrm{M} \beta 2)$ mediated phagocytosis. These opsonins coat the particulate antigen, labelling it for internalisation and eventual degradation by phagocytosis. This process is shown schematically in Figure 1. Phagocytosis can also be triggered by receptors that bind directly to surface determinants of microorganisms, such as mannose receptors, scavenger receptors or Dectin-1 (21). Receptor triggering (Figure 1A) initiates a transient burst of actin polymerization that forms the phagocytic cup (Figure 1B) and provides the force with which membrane ruffles extend to engulf particulate matter. Actin polymerisation continues at pseudopod tips, while depolymerisation of the actin at the base of the phagocytic cup occurs, facilitating the membrane resupply required 
(Figure 1C) (21). Closure of the phagosome occurs when membrane extensions meet, promoted by actin and dynamin activities (Figure 1D), after which the phagosome is internalised by the phagocyte (Figure 1E). After the cell achieves this significant mechanical feat, the phagosome is degraded via series of fission and fusion events with endocytic compartments.

102

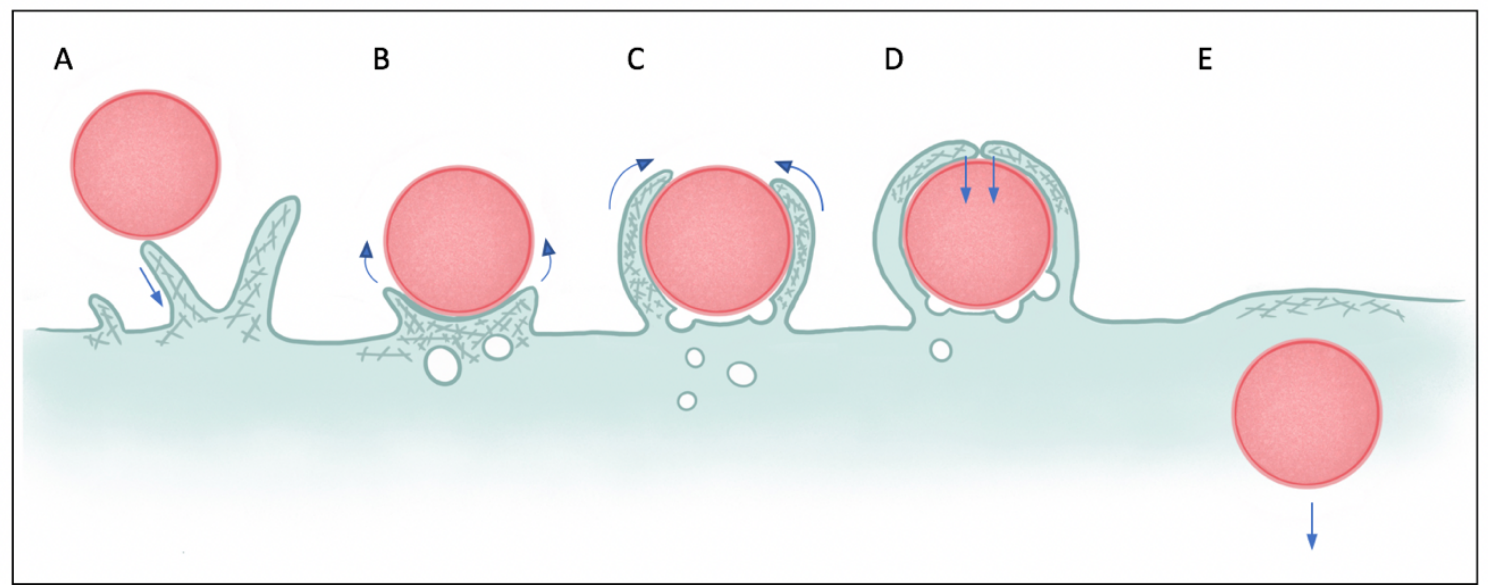

Figure 1: Schematic representation of phagocytosis. Phagocytosis begins with physical contact between phagocyte and target (A) such that ligand-receptor binding can initiate phagocytosis, beginning with a transient burst of actin polymerization that forms the phagocytic cup (B) and provides the force with which membrane folds extend to engulf particulate matter. Actin polymerisation continues at pseudopod tips, while depolymerisation of the actin at the base of the phagocytic cup occurs, facilitating the membrane resupply required (C). Closure of the phagosome occurs when membrane extensions meet (D), after which the phagosome is internalised by the phagocyte (E).

The efficiency of the professional phagocytes in performing these vital immune functions can be significantly reduced in patients with chronic illnesses $(22,23)$. This can be due to microbes co-opting phagocytes to better invade host cells and/or to evade immune responses (24). This is the case in particular after viral infections of macrophages promoting the development of bacterial super-infections. Conversely, improper regulation of macrophage function in a chronic inflammatory environment has been implicated in several diseases including cancer, rheumatoid arthritis and atherosclerosis (25). Given this therapeutic significance, the professional phagocytes have been the subject of intense study in medicine and cell biology. Significant progress has been made in the elucidation of the signalling pathways governing the process, from the triggering of phagocytic receptors to phagosome closure, internalisation and degradation $(1,26)$. More recently however, physical studies investigating the forces involved in the mechanical feats required for phagocytosis to occur have provided new avenues for investigation. Studies featuring force measurement of living phagocytic cells from traditional force measurement methods, such as atomic force microscopy, micropipette aspiration, magnetic and optical tweezers, as well less established and very exciting methods such as traction force microscopy and new variants of these will form the basis of this review. 


\section{Migration studies of the professional phagocytes}

Cells are mechanically attached to neighboring cells and the extracellular matrix (ECM). Forces generated by a cell are transmitted through these adhesions (tractions). Cellular tractions are very small ( $\mathrm{pN}$ to $\mathrm{nN}$ range) and occur across small length scales (nm to $\mu \mathrm{m}$ range) making direct measurement of these forces difficult. A way around this difficulty is to measure the deformations to flexible materials induced by cellular tractions. Cellular tractions can thus be determined provided a substrate of well-defined material properties. A broad family of techniques, operating on this principle, allow for measurement of cellular tractions (27). The majority of migration studies of the professional phagocytes have utilized a technique referred to as traction force microscopy (TFM). As this technique is less commonly used than other more established methods such as atomic force microscopy, or magnetic and optical tweezers, the basic principles will be outlined here. Briefly, in standard (2D) TFM, small $(\sim 200 \mathrm{~nm})$ fluorescent beads are mixed into silicone or polyacrylamide substrates of known stiffness and coated with extracellular matrix proteins to facilitate cellular adhesion. The fluorescent beads serve as fiduciary markers that can be tracked in space and time with optical microscopy. Typically, a TFM experiment requires optical imaging of the distribution of beads at the substrate surface in a stressed state, and the imaging the beads again in an unstressed state, usually after lysing the cell under observation. Computational algorithms are then used to analyse the resulting images and to determine the displacement of the beads and the forces that would be required to cause such displacement. The typical critique of standard TFM is that tractions are collected in 2D and therefore the method is 'blind' to forces exerted in the $\mathrm{z}$ direction. There are two exciting variations to this approach that correct for this limitation, 2.5 and 3D TFM. In 2.5D TFM, the same experimental conditions apply as in standard TFM in that cells exert forces on a planar, or 2D substrate, but bead displacement is observed in $\mathrm{x}, \mathrm{y}$ and $\mathrm{z}$. This requires significantly more complex computation. The result though, is that cell generated forces exerted on the substrate in $x, y$ and $z$ can be quantified (28-30). It is important to note here that there is some confusion in the naming of the TFM variants. In some studies, 2.5D TFM is referred to as ' $3 \mathrm{D}$ TFM' to reflect that forces are measured in $\mathrm{x}, \mathrm{y}$ and $\mathrm{z}$, but as the cellular forces being exerted on a planar substrate, '2.5D TFM' is more appropriate. 'Truly' 3D TFM, the measurement of cell generated forces in $\mathrm{x}, \mathrm{y}$ and $\mathrm{z}$ within a 3D substrate, is both technically and computationally demanding and performed in very few laboratories in the world. The method requires the preparation of porous 3D substrates of known and consistent material properties and very complex computation for the tracking of fiduciary markers in 3D (31). To the best of our knowledge, 2.5D and 3D TFM have not yet been applied to the study of the professional phagocytes of the immune system. As it is standard 2D TFM that is overwhelmingly present in the literature of the professional phagocytes of the immune system, hereafter, when TFM is discussed, it is standard 2D TFM that is being referred to. The differences between the techniques outlined in this section are summarised in Table 1 with references for further reading and some links to open source code helpful to those who wish to get started with TFM.' 


\begin{tabular}{|c|c|c|c|c|}
\hline Technique & Measurement & Major strengths & Major limitations & Refs \\
\hline $\begin{array}{l}\text { Traction force } \\
\text { microscopy (TFM) }\end{array}$ & $\begin{array}{l}\text { Cellular } \\
\text { traction forces } \\
\text { in } \mathrm{x}, \mathrm{y} \text { plane }\end{array}$ & $\begin{array}{l}\text { - Relatively simple } \\
\text { fabrication of substrates, } \\
\text { using standard lab supplies } \\
\text { - Standard fluorescence } \\
\text { microscope for image } \\
\text { acquisition }\end{array}$ & $\begin{array}{l}\text { - Generally computationally } \\
\text { demanding, though some } \\
\text { ImageJ plugins are available } \\
\text { that can be used to get started: } \\
\text { https://sites.google.com/site/q } \\
\text { ingzongtseng/tfm (32) } \\
\text { And some open source MATLAB } \\
\text { code: } \\
\text { https://github.com/dkovari/TF } \\
\text { Matlab(33) } \\
\text { - Requires lysis for } \\
\text { determination of 'null force' } \\
\text { state }\end{array}$ & $\begin{array}{l}(32- \\
37)\end{array}$ \\
\hline$\underbrace{2.5 \mathrm{D} T F M}_{i}$ & $\begin{array}{l}\text { Cellular } \\
\text { traction forces } \\
\text { in } \mathrm{x}, \mathrm{y} \text { and } \mathrm{z}\end{array}$ & $\begin{array}{l}\text { - Relatively simple } \\
\text { fabrication of substrates, } \\
\text { using standard lab supplies }\end{array}$ & $\begin{array}{l}\text { - More computationally } \\
\text { demanding than TFM } \\
\text { - Requires lysis for } \\
\text { determination of 'null force' } \\
\text { state } \\
\text { - Requires confocal microscope } \\
\text { for image acquisition }\end{array}$ & $\begin{array}{l}28- \\
30)\end{array}$ \\
\hline 3D TFM & $\begin{array}{l}\text { Cellular } \\
\text { traction forces } \\
\text { in } x, y \text { and } z \\
\text { within a 3D } \\
\text { matrix }\end{array}$ & $\begin{array}{l}\text { - Near native measurement } \\
\text { of traction forces }\end{array}$ & $\begin{array}{l}\text { - More computationally } \\
\text { demanding than TFM and 2.5D } \\
\text { TFM } \\
\text { - Requires lysis for } \\
\text { determination of 'null force' } \\
\text { state } \\
\text { - Requires confocal microscope } \\
\text { for image acquisition } \\
\text { - Preparation of substrates } \\
\text { more difficult than in TFM }\end{array}$ & (31) \\
\hline Micropillar & $\begin{array}{l}\text { Cellular } \\
\text { traction forces } \\
\text { in } \mathrm{x}, \mathrm{y}\end{array}$ & $\begin{array}{l}\text { - Forces are independent } \\
\text { for each pillar making } \\
\text { computation relatively } \\
\text { simple } \\
\text { - Small tractions easier to } \\
\text { measure than in TFM } \\
\text { - Doesn't require lysis of } \\
\text { cells for determination of } \\
\text { 'null force' state }\end{array}$ & $\begin{array}{l}\text { - Requires microfabrication and } \\
\text { functionalisation of micropillar } \\
\text { substrate }\end{array}$ & $\begin{array}{l}\text { (38, } \\
39)\end{array}$ \\
\hline
\end{tabular}

Table 1: Cellular traction force measurement techniques.

Smith et al. (36) and Jannat et al.(37) used TFM to study the migration of neutrophils.

Neutrophils are key players in the inflammatory response to injury and pathogens. They are activated by chemoattractants leading to firm adhesion and rapid migration (20 $\mu \mathrm{m} / \mathrm{min}$ ). Neutrophils have also been known to turn quickly in response to chemical cues (13). The authors found that neutrophils achieve this motility not through frontal towing but rather by 'tail contraction' or 'rearward-squeezing' where traction forces are concentrated in the cells uropod and the cell is pushed forward through a squeezing mechanism, demonstrated to be dependent on ROCK and myosin activity. The authors also found that the magnitude of neutrophil tractions were very small compared to those generated by mesenchymal cells (consistent with the need to move quickly towards phagocytic targets).

Ricart et al. (39) performed similar experiments on dendritic cells (DCs). DCs are initiators of the adaptive immune response. They are stationed throughout the periphery awaiting pathogen entry after which, they mature and migrate to lymph 
nodes where they orchestrate lymphocyte activation. Given the extensive migration they are required to undertake, it is very important that they can interpret external cues to migrate through different microenvironments. The authors used a micropillar array detector, as they found that the traction forces exerted by DCs were too weak to reliably quantify using TFM. PDMS micropillar arrays were fabricated with an effective stiffness of $\sim 1.5 \mathrm{kPa}$. Tips of the micropillar were microcontact printed with fibronectin to promote cell adhesion. DCs were allowed to adhere and exposed to chemokine gradients and timelapse imaging revealed the deflection of micropillars due to cell migration. Forces were calculated by multiplying the deflection of each individual micropillar by the spring constant of the micropillars. These experiments revealed that the maximal stress was at the leading edge of the cell, an indicator of the towing model of migration, with significantly less force exerted by DCs than neutrophils.

In two studies by Hind et al. $(34,35)$ macrophage migration was studied using TFM. Macrophages play an important role in the innate immune response by clearing pathogens through phagocytosis and activating the adaptive immune response through cytokine production and antigen presentation. They need to be able to migrate to site of infection. The TFM experiments of Hind et al. (34) revealed that the magnitude of macrophage tractions was dependent on the stiffness of the substrate. This result, from experiments with substrates of four different stiffnesses, is important: macrophages migrate through very different microenvironments in the different parts of the organism. Jannat et al. (37) observed the same trend with neutrophils though with substrates of only two different stiffnesses. Like DCs, macrophages were found to migrate using the towing mechanism of motility with the interesting difference that prior to macrophage contraction with which the towing mode of migration begins, macrophages were found to extend and attach a pseudopod to the substrate. The authors also demonstrate that macrophages are mechanoresponsive cells, hypothesing that this ability may offer an advantage to cells that migrate through tissues of significantly different density. In a later publication from the same group, Hind et al. (35) used TFM to study the motility of differently polarized macrophages. Macrophages can become polarized by cues in their environments resulting in functional changes. Two main polarisations were obtained after in vitro treatment: pro-inflammatory M1 macrophages induced with IFNg and LPS, and anti-inflammatory M2 macrophages treated with IL4. M0 macrophages were differentiated with M-CSF and not further activated. The TFM experiments reported by Hind et al. demonstrate that M1 macrophages generate significantly less force than M0 macrophages, which in turn, generate significantly less force than M2 macrophages. The same trend was observed for motility. Related work demonstrated that macrophages use the amoeboid or the mesenchymal migration modes depending of their subsets and activation status (40). More importantly, as the authors state, differences in motility could serve as therapeutic targets in a number of diseases specifically associated with macrophage activity and roles in the different phases of an inflammatory process. This sentiment could be extended to all of the phagocytes discussed here and these studies emphasise the importance of studying the force generation of individual cell types: their motilities differ according to their functions.

\section{Adhesion studies}


Rather than focal adhesions, monocyte-derived macrophages form podosomes. These are F-actin rich cone shaped structures that are $\sim 600 \mathrm{~nm}$ in height, of submicron diameter and form perpendicular to the substrate, surrounded by a ring of integrins and other actin binding proteins (41). These adhesive structures have recently been investigated using atomic force microscopy (AFM). The versatility of this technique in biological applications is long established and as such the operating principles will not be discussed here. A recent and comprehensive overview of AFM in molecular and cell biology applications can be found in Dufrêne et al. (42).

In an AFM and correlative fluorescence microscopy study, Labernadie et al. (43) determined that podosomes are very dynamic, with a typical lifespan of $\sim 10 \mathrm{~min}$ with oscillations in height and stiffness recorded throughout the lifetime of the structure. Average podosome height and stiffness were accurately measured (578 $\pm 209 \mathrm{~nm}$ and $43.8 \pm 9.3 \mathrm{kPa}$ ) and the authors found that these properties did not vary significantly with changes in substrate. These AFM measurements of podosome height and stiffness were performed, as is required with AFM, from the dorsal side. This is possible due to the relative stiffness and significant height of the podosome structure when compared with the plasticity of the overlying plasma membrane. The authors acknowledge that the determination of individual podosome forces is beyond the capability of a traditional AFM setup, as this would require measurement from the ventral side. It seems that this limitation prompted the authors next research direction, as some years later, the authors presented a novel, and complementary, AFM based method called 'protrusion force microscopy' (PFM) to address this point (44). The differences in these two approaches are shown in Table 2.

\begin{tabular}{|l|l|l|}
\hline Method & Atomic force microscopy (AFM) & Protrusion force microscopy (PFM) \\
\hline $\begin{array}{l}\text { Experimental } \\
\text { configuration }\end{array}$ & & \\
\hline $\begin{array}{l}\text { Podosome size } \\
\text { measurement }\end{array}$ & $\begin{array}{l}\text { Dimensions of intracellular podosome } \\
\text { structures measured from dorsal side }\end{array}$ & $\begin{array}{l}\text { Dimensions of extracellular podosome } \\
\text { structures measured from ventral side }\end{array}$ \\
\hline $\begin{array}{l}\text { Force } \\
\text { measurement }\end{array}$ & $\begin{array}{l}\text { Stiffness of podosomes determined by } \\
\text { deflection of cantilever }\end{array}$ & $\begin{array}{l}\text { Protrusion force calculated from } \\
\text { deformations in formvar sheet to which } \\
\text { cell is adhered }\end{array}$ \\
\hline
\end{tabular}

Table 2: Differences between atomic force microscopy (AFM) and protrusion force microscopy (PFM) for podosome studies.

PFM involves the use of AFM to measure local protrusions generated on a compliant formvar sheet by macrophage podosomes. The forces generated by individual podosomes were then estimated using a model that accounted for the mechanical properties of the formvar sheet. It is interesting to note, that the name 'protrusion force microscopy' was chosen by way of analogy with TFM. PFM is indeed complementary to TFM as it addresses its major limitation: that forces in the $\mathrm{z}$ direction are not measured. Given that the dominant adhesive structure in macrophages is the podosome (that exerts force in the $\mathrm{z}$ direction), PFM has the potential to provide additional data on the 
force generation of these cells, that until now have predominantly been investigated using TFM. On application of their new method to living macrophages, Labernadie et al. stiffness of the substrate - the hallmark of mechanosensing activity. The authors also observed that these protrusions oscillate with a constant period and determined that combined actomyosin contraction and actin polymerization were required for their continuation.

\section{Probing the environment}

Cell membrane protrusions can be characterized according to shape. Veil like, several micron broad protrusions are termed ruffles or lamellipodia. Tube like protrusions, varying from a length of a few hundred nanometers, termed microspikes, to several microns long, termed filopodia. Kress et al. (45) used optical tweezers to trap opsonized particles to study the interaction between phagocyte and phagocytic target. The authors used the optical trap to bring particles functionalized with opsonins to trigger different phagocytic pathways into contact with cell membrane protrusions. They found that overwhelmingly, the cells pulled the phagocytic target towards the cell body after ligand receptor binding had occurred, regardless of opsonin type. Their results suggest that the earliest events in all phagocytic pathways share a common mechanism.

Several research groups have applied force measurement to the study of filopodia function with respect to phagocytosis. Filopodia contain long bundles of parallel actin filaments that penetrate deeply into the cytoplasm (46). Cojoc et al. (47) used optical tweezers to measure the force that filopodia exert on a particle in a trap to be no greater than $3 \mathrm{pN}$. In a complementary study using magnetic tweezers, Vonna et al. demonstrated that as filopodia retract, they generate much larger forces over distances as great as $10 \mu \mathrm{m}$. The authors estimated the forces to be greater than $0.5 \mathrm{nN}$ (48). To study this retraction force in more detail, Kress et al. (49) used an optical trap to hold an opsonized particle. The authors measured the force with which filopodia were retracted back into the cell body, after receptor ligand binding had occurred. An interesting Factin-dependent stepwise retraction of filopodia was observed, suggesting that molecular motors power the retraction. The authors also demonstrated that retraction velocity was proportional to the counteracting force, from $\sim 600 \mathrm{~nm} / \mathrm{s}$ at low forces $(<1$ $\mathrm{pN})$ to $\sim 40 \mathrm{~nm} / \mathrm{s}$ at higher forces $(>15 \mathrm{pN})$ explaining the previous variation reported in the literature (50).

\section{Cortical tension, membrane tension \& internalisation}

At the maximal stage of pseudopod/membrane extension in phagocytosis, actin is predominantly located in the tips, having cleared from the base of the phagocytic cup. Once the target particle is fully surrounded, membrane fusion occurs between the pseudopodia and the phagosome is sealed (separated from the plasma membrane). Actin then quickly depolymerizes. It has been hypothesised that the availability of actin is a rate-limiting step as it is recycled from the cup to the tips (51). Another parameter upon which the successful engulfment and internalisation of the particle is dependent is the availability of membrane to create the phagosome. Holevinski and Nelson (52) used 
capacitance measurements to monitor particle uptake of human monocyte-derived macrophages. Their results revealed that the surface of plasma membrane, rather than decreasing after engulfment of a large particle, increased. Bajno et al. (53) first demonstrated that during phagocytosis, recycling vesicles accumulated at the phagocytic cup, suggesting that membrane extension results from internal membranes. Various internal compartments were actually demonstrated to contribute to efficient phagosome formation (54). Cortical tension measurements performed by Herant et al. (55) on neutrophils provided another solution. In these experiments, neutrophils were partially aspirated using a micropipette and the critical pressure difference at which the cell maintains an appendage of stationary lengths in the micropipette is related to the cortical tension through Laplace's law. The experimental configuration, strengths and limitations of such experiments are shown in Table 3. Herant et al. determined that in addition to the trafficking of internal membranes to the phagocytic cup, the extent to which expansion of the plasma membrane surface during phagocytosis takes place can be explained by the release of 'spare' plasma membrane normally sequestered in a reservoir of membrane folds, also used by the cell to probe its environment. Later, internal compartments were revealed to play a role also as signalling platforms important to regulate the local actin dynamics and depolymerisation that is necessary for membrane extension (56).

Shown schematically in Figure 1, there remains some ambiguity about how phagosome closure and internalisation actually occur. Certainly, for fusion and internalisation to take place, force generated by the actin driven protrusions must have directionality (57). A contractile activity was identified by Evans et al. following pseudopod extension during the phagocytosis of yeast (58). More recently, a TFM study performed by Kovari et al. (33) measured the tractions of the J774 macrophage cell line undergoing frustrated phagocytosis. The authors were able to identify and quantify a contractile phase in cells undergoing frustrated phagocytosis, corresponding to maximal traction forces exerted on the substrate, though it should be noted that frustrated phagocytosis is planar, and therefore quite dissimilar from the 3D process. The activity of myosins (59-65) and a build-up of cortical tension $(55,60,66,67)$ have been suggested as the origin of a contractile force required for internalisation. Several myosins are recruited at the site of phagosome formation. MyosinK plays a critical role in efficient phagocytosis of large particles in Dictyostelium discoideum (62). Myosin-II was described to be important for CR3- more than FcR-mediated phagocytosis (65). In a later study by Herant et al. (66), the authors couple their cortical tension measurements with mathematical modelling to propose a model of FcR phagosome closure. They propose several possible models to explain their experimental observations and find that the model that best fits their data is based on a contractile flattening force with molecular motors (possibly, but not necessarily myosins) that are anchored to the cell-particle interface, pulling down on the actin cytoskeleton and pulling the target particle into the cell body.

In further work, Herant et al. (68) demonstrate that Zymosan triggered phagocytosis occurs via a 'protrusive push' mechanism, with particles only internalised after an initial outward push. They contrast this with the 'enveloping embrace' of FcR phagocytosis (66), revealing that these two pathways display different force profiles. While the precise origin of differing force profiles remains unclear, it has long been established that the two most widely characterised phagocytic pathways, triggered by FcR and CR3 receptors, vary considerably in this respect (69). In both of these studies by Herant et al., 
the cortical tension is considered the primary driver of inward motion of the target particle, contrasting with the idea of a molecular motor driven inward pulling force. The authors propose that it is the cortical tension driven tendency of a cell to round up, in addition to the strong adhesion between the target particle and the plasma membrane of the phagocyte, that is the source of target motion into the cell. Later work is in good agreement with this idea, but the biochemical basis of the contractile force remains unclear $(33,70)$. Recently though, using a Total Internal Reflection Fluorescence (TIRF) Microscopy approach in living macrophages $(26,71)$, Marie-Anaïs et al. demonstrated that the last scission step relies on the activity of the GTPase dynamin that acts in concert with F-actin to mediate membrane scission and FcR-phagosome sealing (71).

\begin{tabular}{|c|c|c|c|c|c|}
\hline Technique & Measurement & Force calculation & Major strengths & Major limitations & Refs \\
\hline $\begin{array}{l}\text { Micropipette } \\
\text { aspiration }\end{array}$ & $\begin{array}{l}\text { Cortical/ } \\
\text { membrane } \\
\text { tension }\end{array}$ & $\begin{array}{l}\text { Critical pressure } \\
\text { difference at which } \\
\text { cell maintains an } \\
\text { appendage of } \\
\text { stationary length } \\
\text { in the micropipette } \\
\text { related to cortical } \\
\text { tension through } \\
\text { Laplace's law }\end{array}$ & $\begin{array}{l}\text { - In house setup } \\
\text { can be achieved at } \\
\text { relatively low cost } \\
\text { - Standard } \\
\text { microscopy }\end{array}$ & $\begin{array}{l}\text { - Experimental } \\
\text { conditions far from } \\
\text { native }\end{array}$ & $\begin{array}{l}55 \\
66, \\
68, \\
72, \\
73)\end{array}$ \\
\hline $\begin{array}{l}\text { Superresolved } \\
\text { microparticle TFM }\end{array}$ & $\begin{array}{l}\text { Cell generated } \\
\text { forces during } \\
\text { phagosome } \\
\text { closure }\end{array}$ & $\begin{array}{l}\text { Deformations of } \\
\text { elastic phagocytic } \\
\text { targets of } \\
\text { quantified material } \\
\text { properties } \\
\text { can be used to } \\
\text { infer surface } \\
\text { traction forces }\end{array}$ & $\begin{array}{l}\text { - Near native } \\
\text { conditions } \\
\text { achievable during } \\
\text { measurement }\end{array}$ & $\begin{array}{l}\text { - Computationally } \\
\text { demanding } \\
\text { - Requires } \\
\text { confocal } \\
\text { microscope for } \\
\text { image acquision } \\
\text { - Preparation of } \\
\text { microparticles } \\
\text { requires } \\
\text { specialized } \\
\text { equipment }\end{array}$ & $\begin{array}{l}(74, \\
75)\end{array}$ \\
\hline
\end{tabular}

Table 3: Methods for investigating phagosome closure.

More recently, Vorselen et al.(75) have made observations similar to Herant et al., while presenting a new, and complementary, approach to study this critical phase of internalisation of phagocytic targets. The authors describe a novel strategy, that they name superresolved microparticle TFM, designed for studying ligand dependent cellular interactions at high spatial resolution. Like PFM, this is a method that has its roots in TFM and was developed to address certain limitations in the standard 2D configuration. The method relies on the reliable fabrication of functionalised polyacrylamide spheres of tunable stiffness. As a proof of concept, J774 murine macrophages were exposed to the spheres functionalised with IgG to trigger phagocytosis. Cell induced deformations were observed and used to determine normal and shear stresses associated with phagocytosis. The experimental configuration, strengths and limitations of the method are shown in Table 3. The potential of this technique to be used to determine the role of various actin binding proteins involved in phagocytosis, particularly in the internalisation/contractile phase, in near native conditions, is significant.

\section{Conclusions}

The professional phagocytes of the immune system are responsible for many crucial immune functions which rely on the ability of phagocytes to migrate and adhere to sites 
of infection, dynamically probe their environments to make contact with phagocytic targets, and to perform phagocytosis, a mechanism of internalization of large particles, microorganisms and cellular debris for intracellular degradation. These significant mechanical feats are dependent on actin polymerization to provide the force that drives membrane deformation. The role of the actin cytoskeleton at key stages of these processes has been extensively studied, particularly with regard to migration, membrane protrusions and pseudopod extension. In recent years, researchers of phagocytosis have coupled traditional methods in medicine and cell biology with methods of force measurement, such as atomic and traction force microscopies, optical and magnetic tweezers and micropipette aspiration to perform mechanistic studies of phagocytosis, providing great insight into this essential immune process. There is a great deal that remains unknown about phagocytosis though, particularly around phagosome sealing and particle internalisation. Both the origin of the contractile force and its trigger are undetermined, though myosins, membrane and cortical tension feature in models that have been proposed. Further studies of the forces involved in this dramatic process present an exciting path forward, particularly as new variants of more established techniques are developed, such as in the work of Vorselen et al. (75) and Labernadie et al. (44). It is the design of such live cell experimental methodologies that along with classical biological methods, may in time, be able to reveal the true variety and complexity of this and other processes in the future.

\section{Acknowledgements}

The authors would like to thank Sophie Echène for the lovely illustrations in this review. This work was supported by grants from Centre National de la Recherche Scientifique (CNRS), Institut National de la Santé et de la Recherche Médicale (Inserm), Université Paris Descartes and Agence Nationale de la Recherche (ANR 16-CE13-0007-01) that supported AM for a post-doctoral position.

\section{Declaration}

The authors declare no conflict of interest.

\section{References}

1. Ronald S. Flannagan VJ, and Sergio Grinstein. The Cell Biology of Phagocytosis. Annual Review of Pathology: Mechanisms of Disease. 2012;7(1):61-98.

2. Niedergang F. Phagocytosis. Encyclopedia of Cell Biology. Waltham: Academic Press; 2016. p. 751-7.

3. Poon IKH, Lucas CD, Rossi AG, Ravichandran KS. Apoptotic cell clearance: basic biology and therapeutic potential. Nat Rev Immunol. 2014;14(3):166-80.

4. Bloes DA, Kretschmer D, Peschel A. Enemy attraction: bacterial agonists for leukocyte chemotaxis receptors. Nat Rev Microbiol. 2015;13(2):95-104.

5. Heit B, Liu L, Colarusso P, Puri KD, Kubes P. PI3K accelerates, but is not required for, neutrophil chemotaxis to fMLP. Journal of Cell Science. 2008;121(2):205.

6. Devosse T, Guillabert A, Haene N, Berton A, De Nadai P, Noel S, et al. Formyl Peptide Receptor-Like 2 Is Expressed and Functional in Plasmacytoid Dendritic Cells, Tissue-Specific 
Macrophage Subpopulations, and Eosinophils. The Journal of Immunology.

$470 \quad 2009 ; 182(8): 4974$.

471 7. Ridley AJ. Rho proteins, PI 3-kinases, and monocyte/macrophage motility. FEBS

472 Letters. 2001;498(2):168-71.

473 8. Ridley AJ, Schwartz MA, Burridge K, Firtel RA, Ginsberg MH, Borisy G, et al. Cell

474 Migration: Integrating Signals from Front to Back. Science. 2003;302(5651):1704.

475 9. Pelham RJ, Wang Y-I. Cell locomotion and focal adhesions are regulated by

476 substrate flexibility. Proc Natl Acad Sci U S A. 1997;94(25):13661-5.

477 10. Reinhart-King CA. Chapter 3 Endothelial Cell Adhesion and Migration. Methods in 478 Enzymology. 443: Academic Press; 2008. p. 45-64.

479 11. Reinhart-King CA, Dembo M, Hammer DA. The Dynamics and Mechanics of 480 Endothelial Cell Spreading. Biophys J. 2005;89(1):676-89.

481 12. Lo C-M, Wang H-B, Dembo M, Wang Y-I. Cell Movement Is Guided by the Rigidity of 482 the Substrate. Biophys J. 2000;79(1):144-52.

483 13. Lauffenburger DA, Linderman JJ. Receptors. [electronic resource] : models for 484 binding, trafficking, and signaling: Oxford University Press; 1993.

485 14. Bidan CM, Fratzl M, Coullomb A, Moreau P, Lombard AH, Wang I, et al. Magneto486 active substrates for local mechanical stimulation of living cells. Sci Rep. 2018;8(1):1464.

487 15. Kohyama M, Ise W, Edelson BT, Wilker PR, Hildner K, Mejia C, et al. Role for Spi-C in 488 the development of red pulp macrophages and splenic iron homeostasis. Nature.

489 2009;457(7227):318-21.

490 16. Bilzer M, Roggel F, Gerbes AL. Role of Kupffer cells in host defense and liver disease. 491 Liver International. 2006;26(10):1175-86.

492 17. Gerner Michael Y, Torabi-Parizi P, Germain Ronald N. Strategically Localized Dendritic 493 Cells Promote Rapid T Cell Responses to Lymph-Borne Particulate Antigens. Immunity. 494 2015;42(1):172-85.

495 18. Flannagan RS, Harrison RE, Yip CM, Jaqaman K, Grinstein S. Dynamic macrophage 496 "probing" is required for the efficient capture of phagocytic targets. The Journal of Cell 497 Biology. 2010;191(6):1205.

498 19. Miller YI, Chang M-K, Funk CD, Feramisco JR, Witztum JL. 12/15-Lipoxygenase 499 Translocation Enhances Site-specific Actin Polymerization in Macrophages Phagocytosing 500 Apoptotic Cells. Journal of Biological Chemistry. 2001;276(22):19431-9.

501 20. Nimmerjahn A, Kirchhoff F, Helmchen F. Resting Microglial Cells Are Highly Dynamic 502 Surveillants of Brain Parenchyma in Vivo. Science. 2005;308(5726):1314.

503 21. Jubrail J, Montauban K, Regis-Burgel P, Kurian N, Niedergang F. Characterisation of 504 defective phagocytosis by chronic obstructive pulmonary disease alveolar macrophages.

505 European Respiratory Journal. 2016;48(suppl 60).

506 22. Tabas I, Glass CK. Anti-Inflammatory Therapy in Chronic Disease: Challenges and 507 Opportunities. Science. 2013;339(6116):166.

508 23. Jubrail JK, Nisha; Niedergang, Florence. Macrophage phagocytosis cracking the defect 509 code in COPD. Biomedical Journal. 2017; In press.

510 24. Flannagan RS, Cosio G, Grinstein S. Antimicrobial mechanisms of phagocytes and 511 bacterial evasion strategies. Nat Rev Microbiol. 2009;7(5):355-66.

512 25. Pollard JW. Trophic macrophages in development and disease. Nature Reviews 513 Immunology. 2009;9:259.

514 26. Mularski A M-AF, Mazzolini J and Niedergang, F. Observing frustrated phagocytosis 515 and phagosome formation and closure using total internal reflection fluorescence 
microscopy (TIRFM). In: Rousselet G, editor. Methods in Molecular Biology. In press: Springer; 2018.

518 27. Polacheck WJ, Chen CS. Measuring cell-generated forces: a guide to the available 519 tools. Nat Meth. 2016;13(5):415-23. 28. Legant WR, Choi CK, Miller JS, Shao L, Gao L, Betzig E, et al. Multidimensional traction force microscopy reveals out-of-plane rotational moments about focal adhesions. Proc Natl Acad Sci U S A. 2013;110(3):881-6. High Resolution, Large Deformation 3D Traction Force Microscopy. PLOS ONE. 2014;9(4):e90976.

30. Maskarinec SA, Franck C, Tirrell DA, Ravichandran G. Quantifying cellular traction forces in three dimensions. Proc Natl Acad Sci U S A. 2009;106(52):22108-13.

31. Legant WR, Miller JS, Blakely BL, Cohen DM, Genin GM, Chen CS. Measurement of mechanical tractions exerted by cells in three-dimensional matrices. Nat Meth. 2010;7(12):969-71.

32. Martiel J-L, Leal A, Kurzawa L, Balland M, Wang I, Vignaud T, et al. Measurement of cell traction forces with ImageJ. Methods in Cell Biology. 2015;125:269-87.

33. Kovari DT, Wei W, Chang P, Toro J-S, Beach RF, Chambers D, et al. Frustrated Phagocytic Spreading of J774A-1 Macrophages Ends in Myosin II-Dependent Contraction. Biophys J. 2016;111(12):2698-710.

34. Hind LE, Dembo M, Hammer DA. Macrophage motility is driven by frontal-towing with a force magnitude dependent on substrate stiffness. Integrative Biology. 2015;7(4):44753.

35. Hind LE, Lurier EB, Dembo M, Spiller KL, Hammer DA. Effect of M1-M2 Polarization on the Motility and Traction Stresses of Primary Human Macrophages. Cellular and Molecular Bioengineering. 2016;9(3):455-65.

36. Smith LA, Aranda-Espinoza H, Haun JB, Dembo M, Hammer DA. Neutrophil Traction Stresses are Concentrated in the Uropod during Migration. Biophys J. 2007;92(7):L58-L60.

37. Jannat Risat A, Dembo M, Hammer Daniel A. Traction Forces of Neutrophils Migrating on Compliant Substrates. Biophys J. 2011;101(3):575-84.

38. Gupta M, Kocgozlu L, Sarangi BR, Margadant F, Ashraf M, Ladoux B. Chapter 16 Micropillar substrates: A tool for studying cell mechanobiology. In: Paluch EK, editor. Methods in Cell Biology. 125: Academic Press; 2015. p. 289-308. 39. Ricart Brendon G, Yang Michael T, Hunter Christopher A, Chen Christopher S, Hammer Daniel A. Measuring Traction Forces of Motile Dendritic Cells on Micropost Arrays. Biophys J. 2011;101(11):2620-8.

40. Cougoule C, Van Goethem E, Le Cabec V, Lafouresse F, Dupré L, Mehraj V, et al. Blood leukocytes and macrophages of various phenotypes have distinct abilities to form podosomes and to migrate in 3D environments. European Journal of Cell Biology. 2012;91(11):938-49.

41. Buccione R, Orth JD, McNiven MA. Foot and mouth: podosomes, invadopodia and circular dorsal ruffles. Nat Rev Mol Cell Biol. 2004;5(8):647-57.

42. Dufrene YF, Ando T, Garcia R, Alsteens D, Martinez-Martin D, Engel A, et al. Imaging modes of atomic force microscopy for application in molecular and cell biology. Nat Nano. 2017;12(4):295-307. 
561

562

563

564

565

566

567

568

569

570

571

572

573

574

575

576

577

578

579

580

581

582

583

584

585

586

587

588

589

590

591

592

593

594

595

596

597

598

599

600

601

602

603

604

605

606

43. Labernadie A, Thibault C, Vieu C, Maridonneau-Parini I, Charrière GM. Dynamics of podosome stiffness revealed by atomic force microscopy. Proc Natl Acad Sci U S A. 2010;107(49):21016.

44. Labernadie A, Bouissou A, Delobelle P, Balor S, Voituriez R, Proag A, et al. Protrusion force microscopy reveals oscillatory force generation and mechanosensing activity of human macrophage podosomes. 2014;5:5343.

45. Kress H, Stelzer EHK, Griffiths G, Rohrbach A. Control of relative radiation pressure in optical traps: Application to phagocytic membrane binding studies. Phys Rev E: Stat, Nonlinear, Soft Matter Phys. 2005;71(6):061927.

46. Svitkina TM, Bulanova EA, Chaga OY, Vignjevic DM, Kojima S-i, Vasiliev JM, et al. Mechanism of filopodia initiation by reorganization of a dendritic network. The Journal of Cell Biology. 2003;160(3):409.

47. Cojoc D, Difato F, Ferrari E, Shahapure RB, Laishram J, Righi M, et al. Properties of the Force Exerted by Filopodia and Lamellipodia and the Involvement of Cytoskeletal Components. PLoS One. 2007;2(10).

48. Vonna L, Wiedemann A, Aepfelbacher M, Sackmann E. Micromechanics of filopodia mediated capture of pathogens by macrophages. Eur Biophys J. 2007;36(2):145-51.

49. Kress H, Stelzer EHK, Holzer D, Buss F, Griffiths G, Rohrbach A. Filopodia act as phagocytic tentacles and pull with discrete steps and a load-dependent velocity. Proc Natl Acad Sci U S A. 2007;104(28):11633-8.

50. Ostrowski Philip P, Grinstein S, Freeman Spencer A. Diffusion Barriers, Mechanical Forces, and the Biophysics of Phagocytosis. Developmental Cell. 2016;38(2):135-46.

51. Freeman SA, Grinstein S. Phagocytosis: receptors, signal integration, and the cytoskeleton. Immunological Reviews. 2014;262(1):193-215.

52. Holevinski KO, Nelson DJ. Membrane capacitance changes associated with particle uptake during phagocytosis in macrophages. Biophys J. 1998;75.

53. Bajno L, Peng X-R, Schreiber AD, Moore H-P, Trimble WS, Grinstein S. Focal Exocytosis of Vamp3-Containing Vesicles at Sites of Phagosome Formation. The Journal of Cell Biology. 2000;149(3):697.

54. Braun V, Fraisier V, Raposo G, Hurbain I, Sibarita J-B, Chavrier P, et al. TIVAMP/VAMP7 is required for optimal phagocytosis of opsonised particles in macrophages. The EMBO Journal. 2004;23(21):4166-76.

55. Herant M, Heinrich V, Dembo M. Mechanics of neutrophil phagocytosis: behavior of the cortical tension. Journal of Cell Science. 2005;118(9):1789.

56. Marion S, Mazzolini J, Herit F, Bourdoncle P, Kambou-Pene N, Hailfinger S, et al. The NF-KB Signaling Protein Bcl10 Regulates Actin Dynamics by Controlling AP1 and OCRLBearing Vesicles. Developmental Cell. 2012;23(5):954-67.

57. Levin R, Grinstein S, Canton J. The life cycle of phagosomes: formation, maturation, and resolution. Immunological Reviews. 2016;273(1):156-79.

58. Evans E, Leung A, Zhelev D. Synchrony of cell spreading and contraction force as phagocytes engulf large pathogens. The Journal of Cell Biology. 1993;122(6):1295.

59. Araki N, Hatae T, Furukawa A, Swanson JA. Phosphoinositide-3-kinase-independent contractile activities associated with Fcy-receptor-mediated phagocytosis and macropinocytosis in macrophages. Journal of Cell Science. 2002;116(2):247.

60. Swanson JA, Johnson MT, Beningo K, Post P, Mooseker M, Araki N. A contractile activity that closes phagosomes in macrophages. Journal of Cell Science. 1999;112(3):307. 

Receptor-mediated Phagocytosis in Macrophages. Molecular Biology of the Cell.

\section{2002;13(2):402-11.}

610 62. Boulais J, Trost M, Landry C, Dieckmann R, Levy E, Soldati T, et al. Evolutionary adaptation of phagocytosis modeled the adaptive immune system. Immunity2010. 63. Gopaldass N, Patel D, Kratzke R, Dieckmann R, Hausherr S, Hagedorn M, et al. Dynamin A, Myosin IB and Abp1 couple phagosome maturation to F-actin binding. Traffic. 2012;13(1):120-30. cytoskeletal crosstalk mediated by myosin-I regulates adhesion turnover during phagocytosis. Nature Communications. 2019;10(1):1249.

\section{Olazabal IM, Caron E, May RC, Schilling K, Knecht DA, Machesky LM. Rho-Kinase and} Myosin-II Control Phagocytic Cup Formation during CR, but Not FcyR, Phagocytosis. Current Biology. 2002;12(16):1413-8.

66. Herant M, Heinrich V, Dembo M. Mechanics of neutrophil phagocytosis: experiments and quantitative models. Journal of Cell Science. 2006;119(9):1903.

67. Zhelev DV, Needham D, Hochmuth RM. Role of the membrane cortex in neutrophil deformation in small pipets. Biophys J. 1994;67.

68. Herant M, Lee C-Y, Dembo M, Heinrich V. Protrusive Push versus Enveloping Embrace: Computational Model of Phagocytosis Predicts Key Regulatory Role of Cytoskeletal Membrane Anchors. PLoS Computational Biology. 2011;7(1):e1001068.

69. Allen LA, Aderem A. Molecular definition of distinct cytoskeletal structures involved in complement- and Fc receptor-mediated phagocytosis in macrophages. J Exp Med. 1996;184.

70. Masters TA, Pontes B, Viasnoff V, Li Y, Gauthier NC. Plasma membrane tension orchestrates membrane trafficking, cytoskeletal remodeling, and biochemical signaling during phagocytosis. Proc Natl Acad Sci U S A. 2013;110(29):11875-80.

71. Marie-Anaïs F, Mazzolini J, Herit F, Niedergang F. Dynamin-Actin Cross Talk Contributes to Phagosome Formation and Closure. Traffic. 2016;17(5):487-99.

72. Guevorkian K, Maître JL. Chapter 10 - Micropipette aspiration: A unique tool for exploring cell and tissue mechanics in vivo. In: Lecuit T, editor. Methods in Cell Biology. 139: Academic Press; 2017. p. 187-201.

73. Herant M, Marganski WA, Dembo M. The Mechanics of Neutrophils: Synthetic Modeling of Three Experiments. Biophys J. 2003;84(5):3389-413.

74. Vorselen D, Wang Y, de Jesus MM, Shah PK, Footer MJ, Huse M, et al. Superresolved microparticle traction force microscopy reveals subcellular force patterns in immune celltarget interactions. bioRxiv. 2019:431221. microparticle traction force microsere interaction in phagocytosis. bioRxiv. 2018:431221. 